\title{
Promoter methylation of MGMT, MLH1 and RASSF1A tumor suppressor genes in head and neck squamous cell carcinoma: Pharmacological genome demethylation reduces proliferation of head and neck squamous carcinoma cells
}

\author{
DIMITRIOS KOUTSIMPELAS, WARUT PONGSAPICH, ULF HEINRICH, \\ SYLVIA MANN, WOLF J. MANN and JÜRGEN BRIEGER \\ Department of Otorhinolaryngology, Head and Neck Surgery, \\ University Medical Center of the Johannes Gutenberg University Mainz, 55101 Mainz, Germany
}

Received October 25, 2011; Accepted December 2, 2011

DOI: 10.3892/or.2012.1624

\begin{abstract}
Promoter hypermethylation of tumor suppressor genes (TSGs) is a common feature of primary cancer cells. However, to date the somatic epigenetic events that occur in head and neck squamous cell carcinoma (HNSCC) tumorigenesis have not been well-defined. In the present study, we analyzed the promoter methylation status of the genes mutL homolog 1 (MLH1), Ras-association domain family member 1 (RASSF1A) and O-6-methylguanine-DNA methyltransferase $(M G M T)$ in 23 HNSCC samples, three control tissues and one HNSCC cell line (UM-SCC 33) using methylation-specific PCR (MSP). The expression of the three proteins was quantified by semi-quantitative immunohistochemical analysis. The cell line was treated with the demethylating agent 5-azacytidine (5-Aza) and the methylation status after 5-Aza treatment was analyzed by MSP and DNA sequencing. Proliferation was determined by Alamar blue staining. We found that the $M G M T$ promoter in $57 \%$ of the analyzed primary tumor samples and in the cell line was hypermethylated. The $M L H$ promoter was found to be methylated in one out of $23(4 \%)$ tumor samples while in the examined cell line the $M L H$ promoter was unmethylated. The RASSF1A promoter showed methylation in $13 \%$ of the tumor samples and in the cell line. MGMT expression in the group of tumor samples with a hypermethylated promoter was statistically significantly lower compared to
\end{abstract}

Correspondence to: Dr Dimitrios Koutsimpelas, Department of Otorhinolaryngology, Head and Neck Surgery, University Medical Center of the Johannes Gutenberg University Mainz, Langenbeckstrasse 1, 55101 Mainz, Germany

E-mail: koutsimpelas@hno.klinik.uni-mainz.de

Key words: O-6-methylguanine-DNA methyltransferase, mutL homolog 1, Ras association domain family member 1, tumor suppressor gene, head and neck squamous cell carcinoma, 5-azacytidine the group of tumors with no measured hypermethylation of the MGMT promoter. After treatment of the cell line with the demethylating agent 5-Aza no demethylation of the methylated MGMT and RASSF1A genes were determined by MSP. DNA sequencing verified the MSP results, however, increased numbers of unmethylated $\mathrm{CpG}$ islands in the promoter region of $M G M T$ and RASSF1A were observed. Proliferation was significantly $(\mathrm{p}<0.05)$ reduced after treatment with 5-Aza. In summary, we have shown promoter hypermethylation of the tumor suppressor genes MGMT and RASSF1A in HNSCC, suggesting that this epigenetic inactivation of TSGs may play a role in the development of HNSCC. 5-Aza application resulted in partial demethylation of the MGMT and RASSF1A TSGs and reduced proliferation of the tumor cells suggesting further evaluation of 5-Aza for HNSCC treatment.

\section{Introduction}

Head and neck squamous cell carcinoma (HNSCC) is a common neoplasm associated with exposure to tobacco and alcohol. It accounts for up to 5\% of all newly diagnosed malignancies worldwide and is the sixth most common cancer in the world (1). The incidence of this type of tumor is expected to rise as a result of the increasing number of female and adolescent smokers. Despite considerable advances in diagnosis and treatment of HNSCC, the overall survival rate has remained constant at $60 \%$ over the past 30 years in the United States (2). The lack of progress in head and neck oncology emphasizes the need for basic studies on the molecular biology of HNSCC.

In HNSCC genetic analyses demonstrated the frequent loss of genomic material at several chromosomal loci suggesting the involvement of diverse tumor suppressor genes (TSGs) in the genesis of $\operatorname{HNSCC}(3,4)$. More recent, in addition to genetic alterations, promoter hypermethylation has been recognized as another mechanism of TSG inactivation. Accordingly, several studies have shown that methylation of $\mathrm{CpG}$ islands located within the promoter regions of tumor suppressor genes is a frequent event in the development of HNSCC and other human malignancies (5-7). 
Table I. Patient, specimen and cell line characteristics.

\begin{tabular}{cclll}
\hline & Age & Gender & \multicolumn{1}{c}{ Site } & TNM \\
\hline Patient no. & & & & \\
1 & 54 & Male & Larynx & T3N0M0 \\
2 & 68 & Male & Oropharynx & T1N0M0 \\
3 & 52 & Female & Hypopharynx & T2N2bM0 \\
4 & 70 & Male & Floor of mouth & T1N0M0 \\
5 & 61 & Male & Oropharynx & T2NOM0 \\
6 & 65 & Male & Larynx & T3N0M0 \\
7 & 65 & Male & Hypopharynx & T2N2bM0 \\
8 & 58 & Female & Hypopharynx & T2N1M0 \\
9 & 74 & Male & Oropharynx & T2N2cM0 \\
10 & 77 & Male & Nasal sinus & T2N0M0 \\
11 & 46 & Male & Oropharynx & T2N1M0 \\
12 & 45 & Male & Oropharynx & T3N0M0 \\
13 & 63 & Male & Hypopharynx & T2N0M0 \\
14 & 53 & Male & Floor of mouth & T3N0M0 \\
15 & 51 & Male & Oropharynx & T2N2bM0 \\
16 & 64 & Male & Oropharynx & T4N2bM0 \\
17 & 67 & Male & Tongue & T4N0M0 \\
18 & 65 & Male & Larynx & T3N0M0 \\
19 & 61 & Male & Oropharynx & T1N1M0 \\
20 & 61 & Male & Larynx & T1N0M0 \\
21 & 67 & Female & Larynx & T1N0M0 \\
22 & 61 & Male & Hypopharynx & T3N2bM0 \\
23 & 83 & Female & Oropharynx & T2N1M0 \\
\hline 0 & & & &
\end{tabular}

Control no.

\begin{tabular}{lllc}
24 & NA & Healthy gingiva & - \\
25 & NA & Healthy gingiva & - \\
26 & NA & Healthy gingiva & - \\
Cell line & & & \\
UM-SCC 33 & Female & Nasal sinus & T4N3aM0 \\
\hline
\end{tabular}

NA, not available.

Among multiple TSGs that have been found to be hypermethylated in a variety of malignancies are the RASSF1A and the $M L H 1$ at chromosome arm 3p $(8,9)$ and the MGMT TSG at $10 \mathrm{q}(10)$.

RASSF1A is a member of a new group of RAS effectors which are involved in cell cycle control, microtubule stabilization, cellular adhesion and motility as well as apoptosis. RASSF1A acts as a TSG by controlling mitotic function and decreasing the risk of aneuploidy leading to increased genomic stability (11). $M L H 1$ is a mismatch repair gene, functions to correct replicate mismatches that escape DNA polymerase proofreading, and hence plays an important role in the maintenance of genetic stability (12). The MGMT TSG is a DNA-repair gene, which prevents the alkylation of guanine (13).

To date, reports have revealed varying frequencies of TSG silencing by hypermethylation in HNSCC. The usefulness of the analysis of the promoter methylation status for prognostic purposes has been shown $(14,15)$ as well as normalization of hypermethylation by drugs in cancer patients. e.g., the efficiency of 5-azacytidine (5-Aza, Vidaza ${ }^{\circledR}$ ) and decitabine $\left(\right.$ Dacogen ${ }^{\circledR}$ ) are established for the therapy of acute myeloid leukemia and myelodysplastic syndromes $(16,17)$.

Considering these findings, we examined the methylation status and the expression of MGMT, MLH1 and RASSF1A in 23 HNSCC biopsy samples and in one HNSCC cell line to establish a potential role of the hypermethylated TSGs in HNSCC development. Furthermore, we investigated the possibility of restoring the methylation status of the TSGs by treatment with 5-Aza and the functional impact of 5-Aza treatment on proliferation of the tumor cells.

\section{Materials and methods}

Patients and specimens. A total of 23 patients (19 males, 4 females) with histological confirmed squamous cell carcinoma and one HNSCC cell line were included in this study (for patient and tumor characteristics see Table I). The specimens obtained in the operation room were fixed in formalin for $24 \mathrm{~h}$, paraffin-embedded and used for later analysis. Clinical information was obtained from the patients charts. Patients ranged in age from 45 to 83 (mean age at operation 62). As controls, three samples of healthy gingiva were analyzed. This study was approved by the Institutional Review Board and performed in accordance to the actual version of the declaration of Helsinki. Informed consent was obtained. All patients were operated between March 2005 and April 2006 at the Department of Otorhinolaryngology, Head and Neck Surgery, University Medical Center of the Johannes Gutenberg University Mainz.

Cell culture. For our experiments the cell line UM-SCC 33 derived from squamous cell carcinoma of the head and neck (HNSCC) was used (Table I) $(18,19)$.

The cell line was maintained in DMEM/Ham's F12 (PAA), supplemented with 5\% FCS (Greiner), and antibiotic solution (penicillin $100 \mathrm{U} / \mathrm{ml}$ and streptomycin $100 \mu \mathrm{g} / \mathrm{ml}$, (PAA) at $37^{\circ} \mathrm{C}$ in $5 \% \mathrm{CO}_{2}$. The cell line was treated with 0.2 and $2 \mu \mathrm{M}$ 5-Aza $\left(\right.$ Vidaza $\left.^{\circledR}\right)$ (Sigma-Aldrich) for $72 \mathrm{~h}$.

DNA isolation and bisulfite modification. Genomic DNA was extracted using the DNeasy tissue kit (Qiagen) and $2 \mu \mathrm{g}$ DNA each were subjected for bisulfite treatment (20). Bisulfite modification of genomic DNA converts unmethylated cytidine residues to uridine residues that are then converted to thymidine during subsequent PCR. We used the Epitect ${ }^{\circledR}$ Bisulfite kit (Qiagen). By the use of conversion specific primers during MSP-analysis the methylation status was then analyzed.

MSP (methylation specific PCR). Methylation in the region near the start codon of MGMT, MLHI and RASSF1A was assessed using bisulfite-treated DNA. To increase the sensitivity and specificity we applied a two-step PCR approach. First, we amplified the TSG promoter regions with the primers $M G M T$-outer-F (5'-TGG TA ATT AAG GTA TAG AG-3', upstream), $M G M T$-outer-R (5'-CCA ATC CAC AAT CAC TCA-3', downstream), MLH1-outer-F (5'-TTT TAG GAG TGA AGG AGG-3' upstream, $M L H 1$-outer-R (5'-ATA AAA CCC TAT ACC TAA TC-3', downstream), RASSF1A-outer-F 
(5'-GAG GAG GGG ATG AAG GAG G-3', upstream) and RASSF1A-outer-R (5'-CTC CAA CCA AAT ACA ACC CT-3' downstream).

The PCR conditions were $95^{\circ} \mathrm{C}$ for $5 \mathrm{~min} ; 40$ cycles at $95^{\circ} \mathrm{C}$ for $30 \mathrm{sec}, 53^{\circ} \mathrm{C}$ for $45 \mathrm{sec}$, and $72^{\circ} \mathrm{C}$ for $45 \mathrm{sec}$; and a final extension at $72^{\circ} \mathrm{C}$ for $10 \mathrm{~min}$. Ten microliters of each sample was subjected to the second round of inner PCR amplified with the followingMSP primers: for the MGMT TSG, MSP-F (5'-TTT CGA CGT TCG TAG GTT TTC GC-3' upstream) and MSP-R (5'-GCA CTC TTC CGA AAA CGA AAC G-3', downstream) and unmethylated DNA-specific primers (UMSP), UMSP-F (5'-TTT GTG TTT TGA TGT TTG TAG GTT TTT GT-3', upstream) and UMSP-R (5'-AAC TCC ACA CTC TTC CAA AAA CAA AAC A-3' downstream). For the $M L H 1$ gene MSP analysis was performed with the following primers: MSP-F (5'-ACG TAG ACG TTT TAT TAG GGT CGT-3', upstream), MSP-R (5'-CCT CAT CGT AAC TAC CCG CG-3', downstream), UMSP-F (5'-TTT TGA TGT AGA TGT TTT ATT AGG GTT GT-3', upstream) and UMSP-R (5'-ACC ACC TCA TCA TAA CTA CCC ACA-3' downstream).

For the RASSFIA gene inner PCR was performed with the following primers: MSP-F (5'-GGG TTT TGC GAG AGC GCG-3', upstream), MSP-R (5'-GCT AAC AAA GCG GAA CCG-3' downstream), UMSP-F (5'-GGT TTT GTG AGA GTG TGT TTA G-3', upstream) and UMSP-R (5'-CAC TAA CAA ACA CAA ACC AAA C-3' downstream).

The PCR conditions were $94^{\circ} \mathrm{C}$ for $15 \mathrm{~min} ; 40$ cycles at $94^{\circ} \mathrm{C}$ for $30 \mathrm{sec}, 62^{\circ} \mathrm{C}$ for $30 \mathrm{sec}$, and $72^{\circ} \mathrm{C}$ for $30 \mathrm{sec}$; and a final extension at $72^{\circ} \mathrm{C}$ for $10 \mathrm{~min}$. Primers for MSP and UMSP were as previously described $(10,21,22)$. The sequences of the primers were derived from sequences AL 355531 (MGMT), $\mathrm{AC} 002481$ (RASSF1A) and AB 017806 (MLH1). The $81 \mathrm{bp}$ and 93 bp PCR products of the MGMT analysis as well as the $115 \mathrm{bp}, 124 \mathrm{bp}$ products of the MLH1 inner PCR and the 169 bp products of the RASSF1A analysis, respectively, were separated by electrophoresis on a $2 \%$ agarose gel and stained with ethidium bromide. Distilled water was used as negative control. Bisulfite-treated lymphocyte DNA from healthy volunteers served as a positive control for unmethylated DNA. This DNA was methylated by the use of SssI methyltransferase (NEB) and used after bisulfite modification as a positive control for amplification of methylated DNA.

DNA sequencing. The order of nucleotides in the promoter region of each gene were analyzed by DNA cycle-sequencing using the BigDye ${ }^{\mathrm{TM}}$ kit (ABI, Foster City, CA, USA). Briefly, extracted DNA samples from the cell line before and after treatment with 5-Aza have been modified with sodium bisulfite treatment. Amplification was performed by the use of M13 extended outer primers of MSP-analysis. Sequences were than determined using an ABI capillary sequencer 310 .

Immunohistochemistry. Immunohistochemical analysis of tumor samples was performed using standard procedures. In brief, formalin-fixed, paraffin-embedded tissues were used. Heat-induced antigen retrieval was performed using microwave treatment ( 3 times for $5 \mathrm{~min}$ each, $600 \mathrm{~W}$ in $10 \mathrm{mM}$ citrate buffer, $\mathrm{pH}$ 6.0) of all slides after dewaxing and rehydration followed by blocking of endogenous peroxidase with $3 \% \mathrm{H}_{2} \mathrm{O}_{2}$ /methanol. Pre-incubation with $10 \%$ normal serum and $2 \%$ bovine albumin/PBS for 75 min to avoid unspecific binding, was followed by the incubation with the specific primary antibodies (MGMT, 1:20 BD Pharmingen, NY; MLH1, 1:20, BD Pharmingen; RASSF1A, 1:50, Genway, CA) for $1 \mathrm{~h}$ at room temperature. The slides were consecutively incubated with biotinylated secondary antibody (goat-anti-mouse, 1:250, Dako A/S, Glostrup Denmark) for $45 \mathrm{~min}$ and then for 30 min with streptavidin-peroxidase. The visualization of the immunoreaction was performed with 3,3'-diaminobenzidine. All washing procedures were performed in PBS; dilutions of antibodies were prepared in $2 \%$ bovine albumin/PBS at room temperature. Negative controls were performed as previously described, substituting the primary antibody with PBS.

Quantification of the expression. For evaluation of the MGMTexpression in tumor samples we measured the stained area and intensity of each section in five fields by a computer-based image analysis method, previously described in detail by us (23). In brief, stainings were quantified by the multiplication of the stained area by the staining intensity and expressed as arbitrary units (A.U.).

Alamar blue assay-proliferation. For determination of 5-Aza mediated functional consequences we incubated the cell line UM-SCC 33 for $72 \mathrm{~h}$ with 0.2 or $2 \mu \mathrm{M} 5$-Aza. Briefly, media were changed and 10\% v/v Alamar Blue reagent (Biozol) was added to each well. The Alamar Blue ${ }^{\circledR}$ assay is based on a redox indicator, changing its color from blue (oxidized) to fluorescent red (reduced). After 4-h fluorescence was measured. Color changes are a measure of cellular metabolism, corresponding to the viability and proliferative activity of the cells (24). Each experiment was repeated three times.

Statistics. A one-sided t-test was applied to assess the statistical significance. All calculations were performed using the SAS software, version 6.12 (Statistical Analysis Systems, SAS Institute Inc., Cary, NC, USA). p-values $<0.05$ are indicated.

\section{Results}

To examine if the promoters of MGMT, MLHI and RASSF1A in HNSCC are methylated, we analyzed these tumor suppressor genes for their methylation status in 23 samples of primary HNSCC and one HNSCC cell line by MSP (Table II). We found that the MGMT promoter was methylated in 13 out of the $23(57 \%)$ analyzed primary tumor samples and in the examined cell line. The $M L H 1$ promoter was found to be methylated in one out of the $23(4 \%)$ tumor samples while the $M L H 1$ promoter in the UM-SCC cell line was unmethylated. MSP analysis of the RASSF1A promoter showed promoter methylation in 3 out of $23(13 \%)$ tumor samples and promoter methylation in the cell line (Table II). Fig. 1 shows representative examples of the MSP-analysis. To compare the methylation status, we additionally analyzed three samples of healthy gingiva by MSP-PCR. We found that in all three samples the promoter region of MLH1, RASSF1A and MGMT was unmethylated. DNA sequencing verified the results of the MSP analysis in the UM-SCC 33 cell line. To analyze a possible association of hypermethylated promoter regions and 
Table II. Analysis of RASSF 1A, MLH1 and MGMT promoter methylation by MSP in primary HNSCC and cell lines and MGMT expression.

\begin{tabular}{|c|c|c|c|c|}
\hline & $\begin{array}{c}\text { RASSF1A } \\
\text { methylation }\end{array}$ & $\begin{array}{c}M L H 1 \\
\text { methylation }\end{array}$ & $\begin{array}{c}M G M T \\
\text { methylation }\end{array}$ & $\begin{array}{c}\text { MGMT } \\
\text { expression (A.U) }\end{array}$ \\
\hline \multicolumn{5}{|l|}{ Patient no. } \\
\hline 1 & - & - & - & 3286 \\
\hline 2 & - & - & - & 2596 \\
\hline 3 & - & - & - & 2788 \\
\hline 4 & + & - & - & NA \\
\hline 5 & - & - & - & 1238 \\
\hline 6 & - & - & - & 3485 \\
\hline 7 & - & - & + & 2550 \\
\hline 8 & - & - & + & 1318 \\
\hline 9 & - & - & + & 532 \\
\hline 10 & - & - & - & 2818 \\
\hline 11 & - & - & + & 884 \\
\hline 12 & - & - & + & 1491 \\
\hline 13 & - & - & + & 709 \\
\hline 14 & - & - & + & 865 \\
\hline 15 & - & - & - & 1625 \\
\hline 16 & - & - & + & 478 \\
\hline 17 & - & - & - & 565 \\
\hline 18 & + & - & + & NA \\
\hline 19 & - & + & + & 952 \\
\hline 20 & + & - & - & 1576 \\
\hline 21 & - & - & + & 617 \\
\hline 22 & - & - & + & NA \\
\hline 23 & - & - & + & 1604 \\
\hline \multicolumn{5}{|l|}{ Control no. } \\
\hline 24 & - & - & - & \\
\hline 25 & - & - & - & \\
\hline 26 & - & - & - & \\
\hline \multicolumn{5}{|l|}{ Cell line } \\
\hline UM-SCC 33 & - & - & - & \\
\hline
\end{tabular}

NA, not available; +, yes; -, no. A.U., arbitrary units.

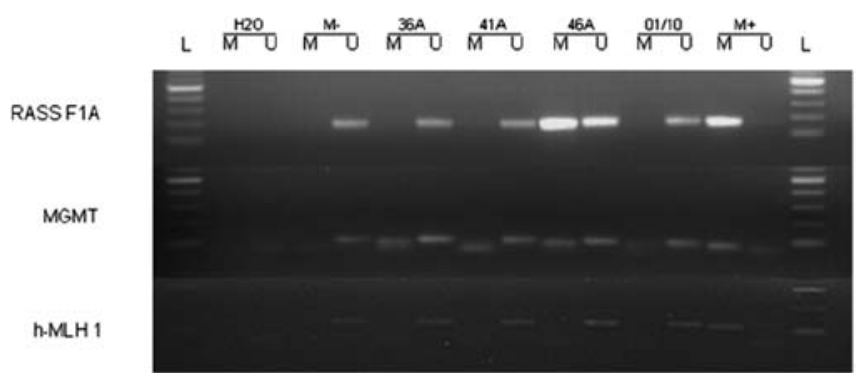

Figure 1. Representative results of MSP analysis of RASSF1A, MGMT and $M L H 1$ in biopsies obtained from primary tumors and cell lines. Bisulphitemodified DNA was amplified with primers specific for unmethylated $(\mathrm{U})$ and methylated (M) DNA. Size of PCR products are $81 \mathrm{bp}$ and $93 \mathrm{bp}$ for $M G M T$, $115 \mathrm{bp}$ and $124 \mathrm{bp}$ for $M L H 1$ and $169 \mathrm{bp}$ for RASSF1A. Sample numbers are indicated above the bands and correspond to those of Table I. L, 100-bp ladder. decreased expression levels, we quantified the MGMT-levels by semi-quantative immunohistochemical analysis.

MGMT expression varied from 478 to 3485 A.U. (mean $1.599 \pm 976$ A.U.). MGMT expression statistically significantly $(\mathrm{p}<0.01)$ decreased in the tumor samples with a hypermethylated MGMT promoter region (Fig. 2). Due to limited tumor samples with hypermethylated $R A S S F 1 A$ and $M L H 1$ promoter regions, no correlation analysis of hypermethylated promoter regions and expression levels was performed.

After treatment of the UM-SCC33 cell line with 5-Aza for $72 \mathrm{~h}$ we observed no demethylating effect by MSP analysis (representative result is shown in Fig. 3A). However, sequence analysis showed that 5-Aza treatment led to an increased number of unmethylated $\mathrm{CpG}$ islands in the methylated promoter region of RASSF1A in the UM-SCC33 cell line 
A
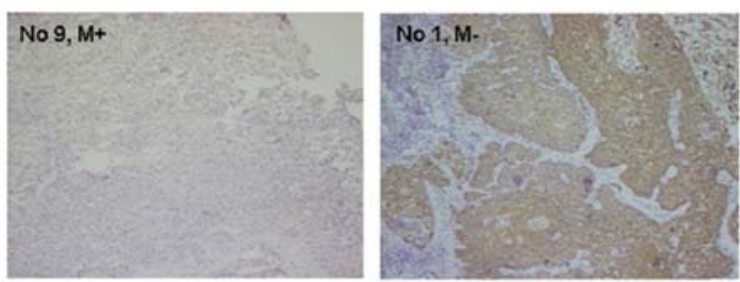

B

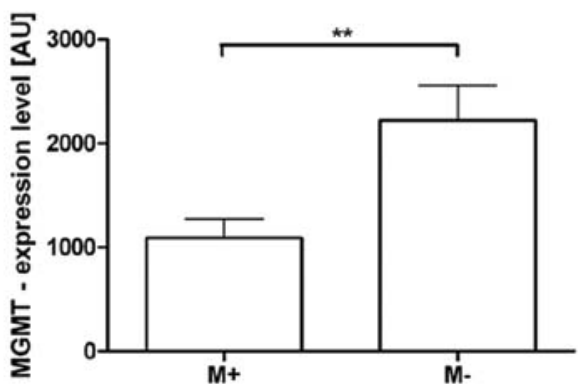

Figure 2. The MGMT expression in tumor samples with a hypermethylated $M G M T$ promoter region is significantly lower than that in tumor samples without hypermethylation of the $M G M T$ promoter region. Shown are representative immunohistochemically analyzed samples (A, x100). Mean values \pm SD in arbitrary units (A.U). Differences were calculated by t-test; ${ }^{* *} \mathrm{p}<0.01$ $\mathrm{M}+$, hypermethylated $M G M T$ promoter region. M-, no hypermethylation of the $M G M T$ promoter region

A

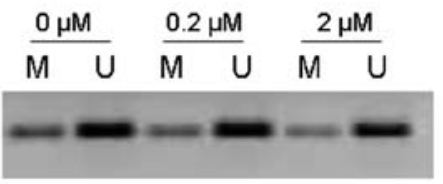

B

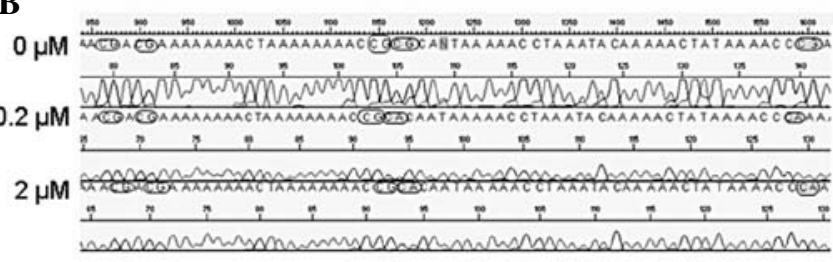

Figure 3. (A) MSP-analysis of UM-SCC 33 with and without 5-Aza after $72 \mathrm{~h}$. No CpG-demethylation was detected. (B) DNA-sequencing of the same samples. CpGs are circled. 5-Aza treatment resulted in partial CpGdemethylation (grey-filled circles).

(Fig. 3B). The MTT assay revealed a tendency for reduced tumor cell proliferation $4 \mathrm{~h}$ after treatment with 5 -Aza for $72 \mathrm{~h}$ at a concentration of $0.2 \mu \mathrm{M}$ (not significant) and a statistically significant reduction $(\mathrm{p}<0.05)$ of the proliferation at the same point of time with the $2 \mu \mathrm{M}$ 5-Aza concentration (Fig. 4).

\section{Discussion}

Aberrations of genomic material as well as epigenetic modifications of genome-like promoter hypermethylations may result in the deregulation of tumor suppressor genes and finally in cancer (14). In HNSCC recurrent chromosomal losses have been described $(3,4,14)$ suggesting the involvement of several tumor suppressor genes in the genesis of HNSCC. In this study we analyzed the methylation status of three potential TSGs. MLH1 is a mismatch repair gene, located at 3p, a

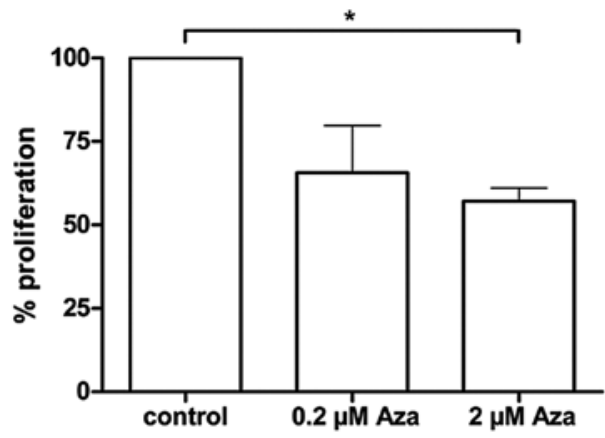

Figure 4. Functional impact of 5-Aza treatment on proliferation of the tumor cells. UM-SCC 33 cells were treated for $72 \mathrm{~h}$ with 5-Aza. The proliferative activity measured by the MTT assay $4 \mathrm{~h}$ after 5-Aza treatment was lowered at both 5-Aza concentrations and statistically significantly reduced at $2 \mu \mathrm{M}$ 5-Aza. Controls were set as $100 \%$. Shown are the mean values \pm SD of three independent experiments performed in triplicate. Differences were calculated by the t-test; ${ }^{\mathrm{p}}<0.05$.

chromosomal arm showing high level of allelic losses in many cases of malignancies $(9,12)$. Several studies reported deletion or hypermethylation of the gene in hereditary colon cancer, gastric, endometrium, prostate but also HNSC cancer (21). The TSG RASSF $1 A$, also located at $3 \mathrm{p}$, plays a major role in the regulation of mitosis and it has been reported to be methylated in the vast majority of lung cancers and to a lesser extent in breast, ovarian and HNSC cancer $(8,11,22) . M G M T$ is a TSG, located at $10 \mathrm{q}$, playing vital roles in preventing induction of mutations and cancer related to alkylating agents $(10,13)$. Aberrations of $M G M T$ have been reported in lung, colon, brain, liver and HNSC cancer (10).

We analyzed the methylation status of these three TSGs in tumor samples from 23 patients with HNSCC and in one cell line by MSP PCR. We found that the MLH1 promoter was methylated in one tumor (4\%) while no methylation could be observed in the cell line.

A direct association between hypermethylation of $\mathrm{MLHI}$ and cancer has been reported in colon cancer but reports on the methylation status of the same gene in HNSCC are inconclusive and have ranged from 0 to $88 \%$. High percentage (88\%) of MLH1 methylation was reported by Liu et al but only in samples previous found to have loss of expression of the gene product (25). Steinmann et al reported that $69 \%$ of the 54 HNSCC samples showed hypermethylation of the $M L H 1$ promoter (26), while two studies with 96 and 57 samples did not find methylation at all $(27,28)$. Thus, our results concerning the $\mathrm{MLHI}$ promoter methylation are in agreement with other reports. The widely divergent findings reported in the literature may be attributed to different sensitivities of the techniques as well as to insufficient DNA quality because of tissue preservation or bisulfite treatment. Furthermore, Wright and Stewart argued the importance of histological grading for $M L H I$ expression, reporting that a high sample number (70\%) lacked $M L H 1$ expression in poorly differentiated colon adenocarcinoma. Thus, the reported MLH1 methylation status may also depend on the variety of the histological grading of a study group in HNSCC (29). Yamamoto et al reported a high risk of developing secondary carcinoma in the gastrointestinal tract, in patients with defective protein expression of $M L H 1$ (30), while in a further study 
a significant correlation between the methylation of mismatch repair genes and multiple oral malignancies was found (31). Since our patient cohort consisted from patients with solitary tumors, that could be a further reason for the very rare $\mathrm{MLHI}$ methylation reported in our study. Taken together, the above data suggest that aberrant $M L H 1$ methylation-mediated transcriptional silencing might play a role in the development of multiple synchronous or metachronous malignancies, but it may be of minor importance for the development of solitary HNSCC lesions.

The methylation of the RASSF1A promoter was also rare in 3 out of $23(13 \%)$ tumor samples while the RASSF1A promoter was found methylated in the UM-SCC 33 cell line. These results are in accordance to the study of Dong et al who reported of RASSF1A methylation in $15 \%$ of primary HNSCC and higher frequency in cell lines (32) and to Hogg et al who reported of $17 \%$ RASSF1A methylation in HNSCC while poorly differentiated HNSCC were more commonly methylated for RASSF1A than moderately and well differentiated HNSCC (8). Steinmann et al also report of $18 \%$ RASSF1A methylation in an analysis of 54 HNSCC tumor samples (26). Notably, Lo et al have reported 14 of 21 primary nasopharyngeal carcinomas to show RASSF1A promoter methylation (33). This difference in the prevalence of the RASSF1A methylation may reflect the known differences in the disease. Hence epigenetic inactivation of RASSF1A plays an important role in the development of cancer but is apparently less important in HNSCC where genes other than RASSF1A may be of greater importance.

The MGMT TSG was found in 13 out of the $23(57 \%)$ analyzed primary tumor samples as well as in the examined cell line methylated. Accordingly, we found statistically significantly decreased protein levels of $M G M T$ in the hypermethylated tumors. In the literature the incidence of $M G M T$ promoter hypermethylation in HNSCC ranged from $18 \%$ to $54 \%(26,34,35)$. Frequent $M G M T$ methylation can increase the sensitivity towards the mutagenic effects of DNA alkylating agents like cigarette smoke nitrosamines. On the other hand, it can facilitate the cytotoxic effects of DNA alkylating chemotherapeutics in patients with malignant astrocytomas, glioma and diffuse large B-cell lymphoma $(36,37)$.

In gastric cancer it has been previously reported that a correlation between $M G M T$ methylation and lymph node metastasis exists (38). It can be hypothesized that in HNSCC the epigenetic loss of MGMT function may increase the mutation rates as a result of an impaired repair of DNA damage induced by cigarette smoke nitrosamines. This may facilitate the cell to acquire an enhanced migration potential and invasiveness. In our patient cohort the MGMT hypermethylated samples were equally divided between nodal positive and nodal negative patients.

The frequent $M G M T$ promoter hypermethylation in our study is in line with the results previously described. Our data suggest that although $M G M T$ silencing by promoter hypermethylation might not be important for the development of nodal metastasis in HNSCC, it might play a role in the tumorigenesis of HNSCC, by increasing the sensitivity towards the mutagenic effects of DNA alkylating agents.

After treatment of the cell line with 5-Aza, no demethylating effect could be shown by MSP. DNA-sequencing of the promoter region of the three TSG in the UM-SCC 33 cell line, after treatment with 5-Aza showed an increase in the number of unmethylated $\mathrm{CpG}$ islands in the methylated promoter region of the RASSF $1 A$ and MGMT TSG in the UM-SCC 33 cell line. This can be explained through the higher sensitivity of DNA-sequencing to reveal such minor changes. The ineffective demethylation results are supported by other studies $(39,40)$. Costello et al reported that only around $40 \%$ of the aberrantly methylated genes can be reactivated by 5 -Aza in cultured cancer cell lines (41). Karpf and Jones (42) reported a similar result in colon cell lines, and they suggested that 5-Aza-treated tumor cell lines may no longer express activating factors required for the transcription of these particular CpG-island carrying genes.

This partial promoter demethylation was accompanied in our study by a significant decrease of proliferative activity. The observed demethylating effect of 5-Aza on the proliferative activity of UM-SCC 33 tumor cell line cannot be attributed only to demethylation of $M G M T$ and $R A S S F 1 A$ promoter, since further hypermethylated TSGs might also be involved. Nevertheless, 5-Aza treatment reduces the proliferative activity of tumor cells with hypermethylated TSG promoter in vitro and shows that 5-Aza treatment may be feasible in the therapy of HNSCC patients with TSG promoter hypermethylation.

The value of demethylating treatment with 5-Aza has previously been shown for hematologic disorders $(16,17)$. In these diseases the reactivation of the TSG p15, an inhibitor of cyclin-dependent kinases, is assumed to be the underlying mode of action. Even though our data revealed only limited demethylating effects through 5-Aza demethylating treatment in HNSCC patients with hypermethylation of TSGs, further studies are warranted to elucidate the potential use of demethylating treatment concepts in the treatment of HNSCC.

\section{Acknowledgements}

We are greatly indebted to Bettina Mros for her excellent technical assistance. This study was funded by a grant provided by the Foundation Tumour Research Head and Neck, Wiesbaden, Germany. The foundation is a non-profit organization. The funders played no role in the experiment design, execution, analysis or preparation of the study.

\section{References}

1. Vokes EE, Weichselbaum RR, Lippman SM and Hong WK: Head and neck cancer. N Engl J Med 328: 184-194, 1993.

2. Jemal A, Siegel R, Xu J and Ward E: Cancer statistics. CA Cancer J Clin 60: 277-300, 2010.

3. Gollin SM: Chromosomal alterations in squamous cell carcinomas of the head and neck: window to the biology of disease. Head Neck 23: 238-253, 2001.

4. Brieger J, Jacob R, Riazimand HS, Essig E, Heinrich UR, Bittinger $F$ and Mann WJ: Chromosomal aberrations in premalignant and malignant squamous epithelium. Cancer Genet Cytogenet 144: 148-155, 2003.

5. Ha PK and Califano JA: Promoter methylation and inactivation of tumour suppressor genes in oral squamous cell carcinoma. Lancet Oncol 7: 77-82, 2006.

6. Esteller M, Corn PG, Baylin SB and Herman JG: A gene hypermethylation profile of human cancer. Cancer Res 61: 3225-3229, 2001.

7. Brieger J, Pongsapich W, Mann SA, Hedrich J, Fruth K, Pogozelski B and Mann WJ: Demethylation treatment restores hicl expression and impairs aggressiveness of head and neck squamous cell carcinoma. Oral Oncol 46: 678-683, 2010. 
8. Hogg RP, Honorio S, Martinez A, Agathanggelou A, Dallol A, Fullwood P, Weichselbaum R, Kuo MJ, Maher ER and Latif F: Frequent $3 p$ allele loss and epigenetic inactivation of the RASSF1A tumour suppressor gene from region $3 \mathrm{p} 21.3$ in head and neck squamous cell carcinoma. Eur J Cancer 38: 1585-1592, 2002.

9. Viswanathan M, Tsuchida N and Shanmugam G: Promoter hypermethylation profile of tumor-associated genes p16, p15, hMLH1 MGMT and E-cadherin in oral squamous cell carcinoma. Int J Cancer 105: 41-46, 2003.

10. Kato K, Hara A, Kuno T , Mori H, Yamashita T, Toida M and Shibata T: Aberrant promoter hypermethylation of p16 and MGMT genes in oral squamous cell carcinomas and the surrounding normal mucosa. J Cancer Res Clin Oncol 132: 735-743, 2006

11. van der Weyden L, Tachibana KK, Gonzalez MA, Adams DJ, $\mathrm{Ng}$ BL, Petty R, Venkitaraman AR, Arends MJ and Bradley A: The RASSF1A isoform of RASSF1 promotes microtubule stability and suppresses tumorigenesis. Mol Cell Biol 25: 8356-8367, 2005.

12. Jiricny $\mathbf{J}$ and Nyström-Lahti M: Mismatch repair defects in cancer. Curr Opin Genet Dev 10: 157-161, 2000.

13. Pegg AE: Mammalian O6-alkylguanine-DNA alkyltransferase: regulation and importance in response to alkylating carcinogenic and therapeutic agents. Cancer Res 50: 6119-6129, 1990.

14. Baylin SB, Esteller M, Rountree MR, Bachman KE, Schuebel K and Herman JG: Aberrant patterns of DNA methylation, chromatin formation and gene expression in cancer. Hum Mol Genet 10: 687-692, 2001.

15. Belinsky SA, Liechty KC, Gentry FD, Wolf HJ, Rogers J, Vu K, Haney J, Kennedy TC, Hirsch FR, Miller Y, et al: Promoter hypermethylation of multiple genes in sputum precedes lung cancer incidence in a high-risk cohort. Cancer Res 66: 3338-3344, 2006

16. Daskalakis M, Nguyen TT, Nguyen C, Guldberg P, Kohler G, Wijermans P, Jones PA and Lubbert M: Demethylation of a hypermethylated $\mathrm{P} 15 / \mathrm{INK} 4 \mathrm{~B}$ gene in patients with myelodysplastic syndrome by 5 -aza-2'-deoxycytidine (decitabine) treatment. Blood 100: 2957-2964, 2002.

17. Ruter B, Wijermans PW and Lubbert M: DNA methylation as a therapeutic target in hematologic disorders: recent results in older patients with myelodysplasia and acute myeloid leukaemia. Int J Hematol 80: 128-135, 2004.

18. Welkoborsky HJ, Jacob R, Riazimand SH, Bernauer HS and Mann WJ: Molecular biologic characteristics of seven new cell lines of squamous cell carcinomas of the head and neck and comparison to fresh tumor tissue. Oncology 65: 60-71, 2003.

19. Lin CJ, Grandis JR, Carey TE, Gollin SM, Whiteside TL, Koch WM, Ferris RL and Lai SY: Head and neck squamous cell carcinoma cell lines: established models and rationale for selection. Head Neck 29: 163-188, 2007.

20. Herman JG, Graff JR, Myöhänen S, Nelkin BD and Baylin SB: Methylation-specific PCR: a novel PCR assay for methylation status of CpG islands. Proc Natl Acad Sci USA 93: 9821-9826, 1996.

21. Nan HM, Song YJ, Yun HY, Park JS and Kim H: Effects of dietary intake and genetic factors on hypermethylation of the hMLH1 gene promoter in gastric cancer. World J Gastroenterol 11: 3834-3841,2005.

22. Burbee DG, Forgacs E, Zöchbauer-Müller S, Shivakumar L, Fong K, Gao B, Randle D, Kondo M, Virmani A, Bader S, et al: Epigenetic inactivation of RASSF1A in lung and breast cancers and malignant phenotype suppression. J Natl Cancer Inst 93: 691-699, 2001

23. Gosepath J, Brieger J, Lehr HA and Mann WJ: Expression, localization and significance of vascular permeability/vascular endothelial growth factor in nasal polyps. Am J Rhinol 19: 7-13, 2005.

24. Ahmed SA, Gogal RM and Walsh JE: A new rapid and simple non-radioactive assay to monitor and determine the proliferation of lymphocytes: an alternative to $\left[{ }^{3} \mathrm{H}\right]$ thymidine incorporation assay. J Immunol Methods 170: 211-224, 1994.

25. Liu K, Zuo C, Luo QK, Suen JY, Hanna E and Fan CY: Promoter hypermethylation and inactivation of hMLH1, a DNA mismatch repair gene, in head and neck squamous cell carcinoma. Diagn Mol Pathol 12: 50-56, 2003.
26. Steinmann K, Sandner A, Schagdarsurengin U and Dammann RH Frequent promoter hypermethylation of tumor-related genes in head and neck squamous cell carcinoma. Oncol Rep 22: 1519-1526, 2009.

27. Ogi K, Toyota M, Ohe-Toyota M, Tanaka N, Noguchi M, Sonoda T, Kohama G and Tokino T: Aberrant methylation of multiple genes and clinicopathological features in oral squamous cell carcinoma. Clin Cancer Res 8: 3164-3171, 2002.

28. Wang Y, Irish J, MacMillan C, Brown D, Xuan Y, Boyington C, Gullane P and Kamel-Reid S: High frequency of microsatellite instability in young patients with head-and-neck squamous-cell carcinoma: lack of involvement of the mismatch repair genes hMLH1 and hMSH2. Int J Cancer 93: 353-360, 2001.

29. Wright CL and Stewart ID: Histopathology and mismatch repair status of 458 consecutive colorectal carcinomas. Am J Surg Pathol 27: 1393-1406, 2003.

30. Yamamoto M, Taguchi K, Baba H, Endo K, Kohnoe S, Okamura T and Maehara Y: Loss of protein expression of hMLH1 and hMSH2 with double primary carcinomas of the stomach and colorectum. Oncol Rep 16: 41-47, 2006.

31. Czerninski R, Krichevsky S, Ashhab Y, Gazit D, Patel V and Ben-Yehuda D: Promoter hypermethylation of mismatch repair genes, hMLH1 and hMSH2 in oral squamous cell carcinoma. Oral Dis 15: 206-213, 2009

32. Dong SM, Sun DI, Benoit NE, Kuzmin I, Lerman MI and Sidransky D: Epigenetic inactivation of RASSF1A in head and neck cancer. Clin Cancer Res 9: 3635-3640, 2003.

33. Lo KW, Kwong J, Hui AB, Chan SY, To KF, Chan AS, Chow LS, Teo PM, Johnson PJ and Huang DP: High frequency of promoter hypermethylation of RASSF1A in nasopharyngeal carcinoma. Cancer Res 61: 3877-3881, 2001.

34. Zuo C, Ai L, Ratliff P, Suen JY, Hanna E, Brent TP and Fan CY: O6-methylguanine-DNA methyltransferase gene: epigenetic silencing and prognostic value in head and neck squamous cell carcinoma. Cancer Epidemiol Biomarkers Prev 13: 967-975, 2004.

35. Paluszczak J, Misiak P, Wierzbicka M, Woźniak A and Baer-Dubowska W: Frequent hypermethylation of DAPK, RARbeta, MGMT, RASSF1A and FHIT in laryngeal squamous cell carcinomas and adjacent normal mucosa. Oral Oncol 47: 104-107, 2011.

36. Esteller M, Gaidano G, Goodman SN, Zagonel V, Capello D, Botto B, Rossi D, Gloghini A, Vitolo U, Carbone A, et al: Hypermethylation of the DNA repair gene $\mathrm{O}(6)$-methylguanine DNA methyltransferase and survival of patients with diffuse large B-cell lymphoma. J Natl Cancer Inst 94: 26-32, 2002.

37. Esteller M, Garcia-Foncillas J, Andion E, Goodman SN, Hidalgo OF, Vanaclocha V, Baylin SB and Herman JG: Inactivation of the DNA-repair gene MGMT and the clinical response of gliomas to alkylating agents. N Engl J Med 343: 1350-1354, 2000

38. Park TJ, Han SU, Cho YK, Paik WK, Kim YB and Lim IK: Methylation of $\mathrm{O}(6)$-methylguanine-DNA methyltransferase gene is associated significantly with K-ras mutation, lymph node invasion, tumor staging, and disease free survival in patients with gastric carcinoma. Cancer 92: 2760-2768, 2001.

39. Cameron EE, Bachman KE, Myöhänen S, Herman JG and Baylin SB: Synergy of demethylation and histone deacetylase inhibition in the re-expression of genes silenced in cancer. Nat Genet 21: 103-107, 1999.

40. Shen WJ, Dai DQ, Teng Y and Liu HB: Regulation of demethylation and re-expression of RASSF1A gene in gastric cancer cell lines by combined treatment of 5-Aza-CdR and $\mathrm{NaB}$. World $\mathrm{J}$ Gastroenterol 14: 595-600, 2008.

41. Costello JF, Frühwald MC, Smiraglia DJ, Rush LJ, Robertson GP, Gao X, Wright FA, Feramisco JD, Peltomäki P, Lang JC, et al: Aberrant CpG-island methylation has non-random and tumourtype-specific patterns. Nat Genet 24: 132-138, 2000.

42. Karpf AR and Jones DA: Reactivating the expression of methylation silenced genes in human cancer. Oncogene 21: 5496-5503, 2002 . 